\title{
Pharmacovigilance analysis of adverse event reports for aliskiren hemifumarate, a first-in-class direct renin inhibitor
}

This article was published in the following Dove Press journal:

Therapeutics and Clinical Risk Management

8 August 201I

Number of times this article has been viewed

\author{
Ayad K Ali \\ Department of Pharmaceutical \\ Outcomes and Policy, College \\ of Pharmacy, University of Florida, \\ Gainesville, FL, USA
}

Background: The purpose of this study was to examine the postmarketing safety profile of aliskiren hemifumarate, a first-in-class direct renin inhibitor.

Methods: The US Adverse Event Reporting System (AERS) was utilized to conduct a retrospective pharmacovigilance analysis by applying the Multi-item Gamma Poisson Shrinker data mining algorithm to calculate empiric Bayes geometric mean (EBGM) values of aliskirenrelated adverse event reports. Reports received from January 2007 through December 2008 are included in this analysis.

Results: In total, 1592 reports for aliskiren are identified in the AERS. Aliskiren was associated with reports of angioedema (EBGM 3.9, 95\% confidence interval [CI] 3.2-4.7) and renal dysfunction (EBGM 3.4, 95\% CI 2.6-4.5). Reports of hyperkalemia, dry cough, and diarrhea were also linked to aliskiren (EBGM 7.4, 95\% CI 3.4-13.0, EBGM 11.0, 95\% CI 7.8-14.2, EBGM 4.3, 95\% CI 3.2-5.8, respectively).

Conclusion: Angioedema and renal dysfunction are potential adverse events associated with exposure to aliskiren. Patients with signs and symptoms of angioedema should stop aliskiren and seek urgent medical help. Aliskiren should not be used by patients with a risk of renal impairment. Additional studies are warranted to quantify further the risk of these events in patients with hypertension.

Keywords: aliskiren, postmarketing safety surveillance, adverse event reporting system

\section{Introduction}

New molecular entities are therapeutic moieties in pharmaceutical dosage forms that have not previously been approved for marketing in the US. ${ }^{1}$ Because of the inherent limitations of premarketing clinical (Phase I-III) studies, including the nonrepresentativeness of the study population and the relatively short duration of study follow-up, the safety and efficacy of new molecular entities are not thoroughly established prior to approval. The process of detection, assessment, and prevention of both potential and actual adverse events of pharmaceutical products is termed pharmacovigilance. ${ }^{2}$ When this process is implemented during the lifecycle of the product after approval, it is termed postmarketing safety surveillance or a Phase IV study, and usually begins when the product enters the market. ${ }^{3}$ While on the market, the utilization and outcomes of the product will be exposed to multiple efficacy and safety modifiers that stimulate and worsen adverse drug reactions in many ways, including medication errors and lack of adherence.

In March 2007, Novartis Pharmaceuticals developed aliskiren hemifumarate as the first-in-class direct renin inhibitor indicated for the treatment of hypertension, alone 
or with other antihypertensive medications. The US Food and Drug Administration (FDA) approved the product as a new molecular entity under the brand names Tekturna ${ }^{\circledR}$ and Tekturna $\mathrm{HCT}^{\circledR}$ (a single-pill combination of aliskiren and hydrochlorothiazide). ${ }^{4,5}$ In Europe and Japan, Rasilez ${ }^{\circledR}$ was the approved brand name. ${ }^{6}$ Subsequently, the FDA approved Valturna $^{\circledR}$, a single-pill combination of aliskiren and valsartan. ${ }^{7}$ Aliskiren is one of the novel agents that modulate the reninangiotensin-aldosterone system.

Reports of renal adverse reactions and hyperkalemia are documented for drugs affecting the renin-angiotensinaldosterone system, including angiotensin-converting enzyme inhibitors, angiotensin II receptor antagonists, and aldosterone antagonists. ${ }^{8}$ Rare but serious angioedema and other allergic reactions are also recognized for angiotensinconverting enzyme inhibitors. ${ }^{9,10}$ By virtue of its mode of action, aliskiren modulates the renin-angiotensin-aldosterone system, and could have the same renal and metabolic safety profiles. Early in 2009, both the European Medicines Agency and the Medicines and Healthcare Products Regulatory Agency in the United Kingdom alerted health care professionals and consumers about the increasing risk of acute renal failure and serious angioedema as adverse reactions of treatment with aliskiren. ${ }^{11-13}$

Because of the inherent significance of postmarketing safety surveillance, the FDA Center for Drug Evaluation and Research launched the Adverse Event Reporting System (AERS) as a key tool for postmarketing safety surveillance of all approved pharmaceutical products. Furthermore, in January 2007, the FDA instigated a pilot program to assess the value of regular postmarketing safety surveillance for new molecular entities..$^{14}$ As a supplemental source of information for the FDA pilot program and health care professionals, this retrospective pharmacovigilance study aims to evaluate the safety profile of aliskiren hemifumarate by utilizing the AERS to assess reports of aliskiren-related adverse drug reactions submitted during the period January 2007 through December 2008, and implementing the systematic Multi-item Gamma Poisson Shrinker (MGPS) methodology to detect the magnitude of aliskiren-adverse drug reaction associations in the AERS during the study period.

\section{Methods}

\section{Data source}

The AERS is a voluntary reporting system consisting of a database of spontaneous reports of adverse drug events maintained by the FDA. ${ }^{15}$ Reports are received from manufacturers, patients, physicians, pharmacists, and other health care professionals throughout the world, with the majority of reports being received from within the US. AERS is considered a key tool for postmarketing safety surveillance of all approved pharmaceutical products. The Medical Dictionary for Regulatory Activities (MedDRA) Preferred Terms coding scheme is utilized to enter the adverse drug reaction reports in the AERS database. ${ }^{16}$ The datasets are published quarterly on the AERS website with nonidentifiable information, including demographic details about the patient who experienced the adverse drug reaction and the MedDRA Preferred Term that best describes the adverse drug reaction, as well as the indication for the reported product, the outcome of the event (which describes the severity of the adverse drug reaction), information about the pharmaceutical product, including product name (generic and brand), route, dose, duration of exposure, and primary role of the drug in the reported adverse drug reaction (primary, secondary, concomitant, or interacting), information about the reporter, including occupation and country, and type of submitted report (expedited, periodic, or direct). ${ }^{17,18}$

\section{Identifying exposure}

Aliskiren was marketed under two brand names, Tekturna and Rasilez. In March 2007, Tekturna was approved for the treatment of hypertension in the US. In August 2007, Rasilez was approved as an antihypertensive in the European Union. Two years later, Rasilez was approved for marketing in Japan. In January 2008, the FDA approved Tekturna HCT as a second-line treatment of hypertension. The same product was approved in the European Union one year later. The FDA has approved the indication of Tekturna HCT as initial treatment for hypertension in patients who need combination antihypertensive therapy. In September 2009, Valturna was approved by the FDA as a single-pill combination of aliskiren and valsartan, an angiotensin II receptor antagonist for the treatment of hypertension. ${ }^{6,7}$

Reports received during the period January 2007 through December 2008 are included in this study. Reports for aliskiren are identified using the keywords "aliskiren", "Tekturna", and "Rasilez" in the drug name variable within the dataset. Other drugs affecting the renin-angiotensinaldosterone system are also identified within the same dataset using the verbatim names for each individual class members, eg, benazepril hydrochloride (Lotensin ${ }^{\circledR}$ ) for angiotensinconverting enzyme inhibitors, eprosartan mesylate $\left(\right.$ Teveten $\left.^{\circledR}\right)$ for angiotensin II receptor antagonists, and spironolactone (Aldactone $^{\circledR}$ ) for aldosterone antagonists. 


\section{Identifying adverse drug reactions}

Reports for specific adverse drug reactions were identified by the MedDRA Preferred Terms utilized in the dataset. Clinical judgment was applied to include specific MedDRA Preferred Terms for the signs and symptoms of angioedema and renal dysfunction.

\section{MGPS data mining algorithm}

It is impractical and valueless to quantify the risk of adverse drug reactions reported in the AERS utilizing conventional analysis methods, because of the inaccurate number of the numerator (number of adverse drug reactions), lack of information about the denominator (number of patients exposed to aliskiren), and background rate of the adverse drug reaction in the study population. ${ }^{19}$ Alternatively, the Multi-item Gamma Poisson Shrinker (MGPS) data mining algorithm implements empiric Bayesian models to screen for associations between the drug and previously unidentified adverse drug reactions. ${ }^{20}$ The MGPS calculates empiric Bayes geometric mean (EBGM) values, which are the ratios of the observed to the expected number of drug-event pairs (reporting ratios). The MGPS adjusts for differences in reporting rates by stratifying the expected rates by variables in the dataset, eg, demographics and reporting quarter/year. This adjustment shrinks each reporting ratio towards 1 . This conservative approach considers EBGM values $\geq 2.0$ to be the safety signal threshold. ${ }^{21}$ EBGM values are reported with their $95 \%$ confidence intervals $(\mathrm{CI})$.
Higher values denote a stronger association between the drug and the reported adverse drug reaction. ${ }^{22}$

\section{Data analysis}

AERS datasets were cleaned from duplicated reports, merged, and annexed into one major dataset that covers the study period; descriptive statistics were performed to examine adverse drug reaction reporting patterns for aliskiren. These steps were performed using SAS software, version 9.2 of the SAS System for Windows (2010 SAS Institute Inc, Cary, NC). The web-based Visual Data Mining Environment (WebVDME, 5.0) was applied to conduct the MGPS data mining algorithm, and the reporting ratios (EBGM values) were estimated with their $95 \%$ CI (EB05, EB95). ${ }^{23}$

\section{Results \\ Overview of adverse drug reaction reports}

From January 2007 through December 2008, the AERS received 4,178,542 adverse event reports, including 2154 reports for aliskiren. About 74\% (1592) of aliskiren reports had valid MedDRA Preferred Terms for adverse events. The trend of reporting for aliskiren is presented in Figure 1, which indicates an increase in reporting during the last quarter of 2007, followed by a decline during the subsequent year.

The majority of aliskiren users were elderly females (66.1\%) of mean age 68 years (95\% CI 66-70), in whom

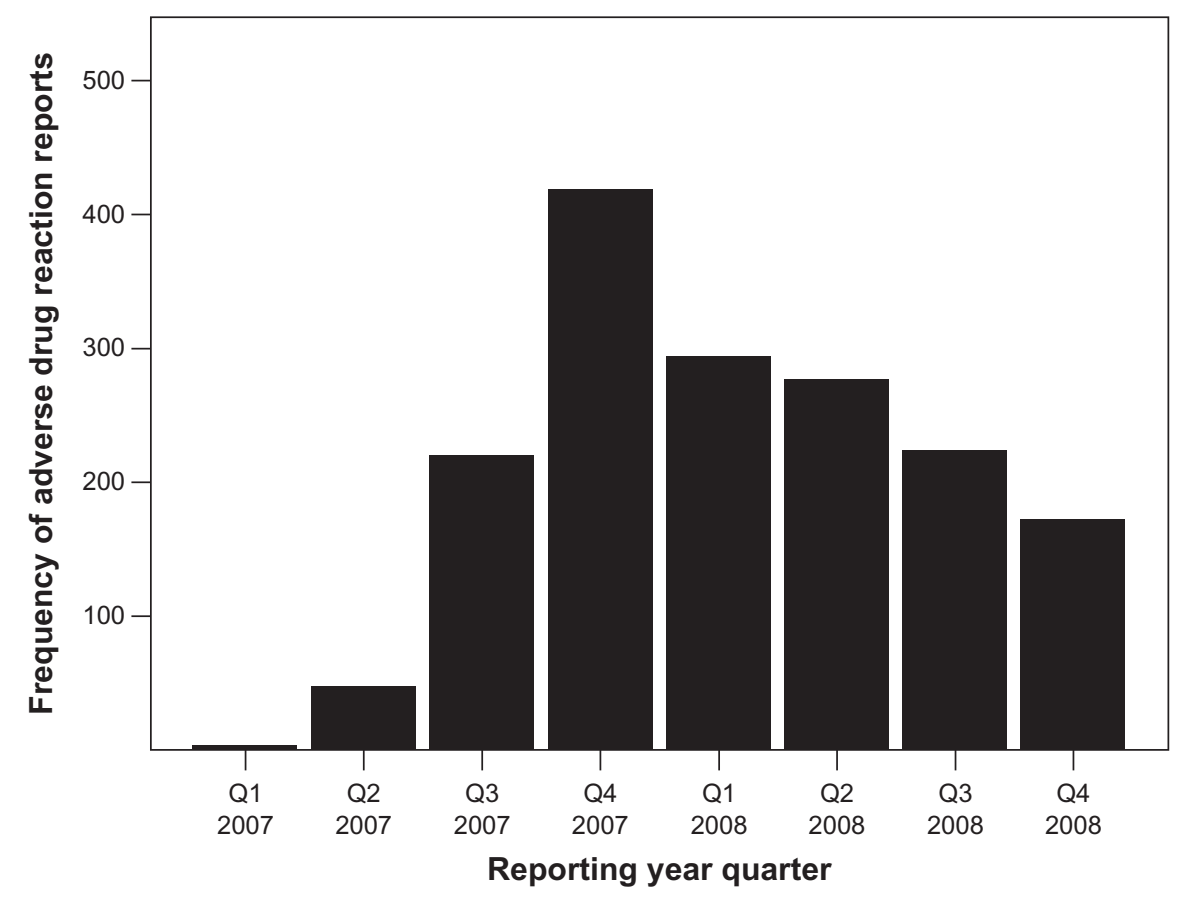

Figure I Trend of adverse event reports for aliskiren in the US Adverse Event Reporting System for 2007-2008. 
the predominant indication of aliskiren was hypertension (95.6\% of reports). The vast majority of the reports were received from within the US (91\%), exclusively for Tekturna, while Rasilez-related reports were received from overseas, specifically the European Union, Canada, and South America. Consumers, including patients and their caregivers, represented the main reporting entities for aliskiren-related reports, where $56 \%$ of reports were directly submitted by consumers. Among health care professionals, physicians and pharmacists reported $38 \%$ and $3 \%$ of the direct reports, respectively. Other health care professionals, including nurses, submitted $4.3 \%$ of the adverse drug reaction reports. Most of the reports that were submitted by the manufacturer to the FDA were periodic, ie, received quarterly (72.2\%). Expedited reports that are received within 15 days of an adverse drug reaction represented about $28 \%$ of the manufacturer-submitted reports. Expedited reports include unlabeled and serious events. Aliskiren was administered orally in tablet form with a dosing range of 75-600 mg, and an aliskiren/hydrochlorothiazide dosing range of 150/12.5-300/25 mg per day. Among reports with valid dosage information, about $43 \%$ consisted of patients exposed to a $150 \mathrm{mg}$ daily dose of aliskiren, compared with about $17 \%$ of exposures to the $300 \mathrm{mg}$ daily dose. Table 1 describes the reports for aliskiren received during the study

Table I Description of adverse event reports for aliskiren in the US Adverse Event Reporting System for 2007-2008

\begin{tabular}{ll}
\hline Characteristics & $\mathbf{n}(\%)^{*}$ \\
\hline Patient age (years) & $17(5.6)$ \\
$20-44$ & $98(32.1)$ \\
$45-64$ & $162(53.1)$ \\
$65-84$ & $28(9.2)$ \\
$85-100$ & \\
Patient gender & $692(66.1)$ \\
Female & $355(33.9)$ \\
Male & \\
Report types & $328(27.4)$ \\
Expedited & $854(71.2)$ \\
Periodic & $17(1.4)$ \\
Direct & $131(28.4)$ \\
Serious & \\
Reporter profession & $429(37.6)$ \\
Physician & $29(2.5)$ \\
Pharmacist & $49(4.3)$ \\
Other health care provider & $633(55.5)$ \\
Consumer & $1(0.1)$ \\
Lawyer & $1082(90.9)$ \\
Reporter country & $108(9.1)$ \\
United States & \\
Overseas &
\end{tabular}

Note: *Percentage of reports within characteristic category. period. Adverse effects with a reporting frequency of $\geq 10$ reports during the study period are listed by organ system class in Table 2.

\section{Angioedema}

Angioedema is a rare allergic reaction to angiotensin-converting enzyme inhibitors and angiotensin II receptor antagonists that causes swelling of the face, throat, and sometimes the extremities. Laryngeal angioedema is a serious adverse drug reaction because it causes suffocation and death. During the analysis period, aliskiren was associated with 36 reports of angioedema. Reports for the signs and symptoms of angioedema were: peripheral edema $(\mathrm{n}=28)$, dyspnea $(15)$, lip swelling (11), dysphagia (7), joint swelling (7), face swelling (6),

Table 2 Distribution of adverse event reports for aliskiren by organ system class in the US Adverse Event Reporting System for 2007-2008

\begin{tabular}{|c|c|c|}
\hline Body system & Adverse event MedDRA term & $\mathbf{n}$ \\
\hline \multirow[t]{4}{*}{ Body as a whole } & Asthenia & 27 \\
\hline & Alopecia & 22 \\
\hline & Fatigue & 21 \\
\hline & Feeling abnormal & 10 \\
\hline \multirow[t]{7}{*}{ Cardiovascular } & Hypertension & 74 \\
\hline & Blood pressure & 69 \\
\hline & inadequately controlled & \\
\hline & Hypotension & 38 \\
\hline & Cerebrovascular accident & 13 \\
\hline & Hypertensive crisis & 10 \\
\hline & Blood pressure fluctuation & 10 \\
\hline \multirow[t]{5}{*}{ Gastrointestinal } & Diarrhea & 49 \\
\hline & Abdominal pain & 34 \\
\hline & Nausea & 17 \\
\hline & Dyspepsia & 17 \\
\hline & Increased hepatic enzyme & 13 \\
\hline \multirow[t]{4}{*}{ Central nervous } & Dizziness & 61 \\
\hline & Headache & 24 \\
\hline & Anxiety & 13 \\
\hline & Depression & II \\
\hline \multirow[t]{2}{*}{ Respiratory } & Cough & 44 \\
\hline & Dyspnea & 15 \\
\hline \multirow[t]{2}{*}{ Metabolic } & Hyponatremia & 17 \\
\hline & Hyperkalemia & 16 \\
\hline \multirow[t]{2}{*}{ Urogenital } & Acute renal failure & 29 \\
\hline & Increased blood creatinine & 29 \\
\hline \multirow[t]{3}{*}{ Musculoskeletal } & Arthralgia & 17 \\
\hline & Myalgia & 15 \\
\hline & Pain in extremity & 10 \\
\hline \multirow[t]{5}{*}{ Skin } & Angioedema & 36 \\
\hline & Peripheral edema & 28 \\
\hline & Rash & 25 \\
\hline & Lip swelling & II \\
\hline & Pruritus & 10 \\
\hline Other & Drug ineffective & 44 \\
\hline
\end{tabular}

Abbreviation: MedDRA, Medical Dictionary for Regulatory Activities. 
pharyngeal edema (5), eyelid edema (5), throat tightness (4), exertional dyspnea (2), mouth edema (2), swollen tongue (2), periorbital edema (1), and laryngospasm (1). The total number of identified reports for potential aliskiren-linked angioedema is 132 ( $8.3 \%$ of total reports). The majority of reported cases for angioedema (81\%) was associated with a daily aliskiren dose of $150 \mathrm{mg}$. Two reports of death, two reports of lifethreatening events, and 12 reports of hospitalization were attributed to angioedema.

\section{Renal dysfunction}

Reports of aliskiren-linked renal dysfunction were identified as: acute renal failure $(\mathrm{n}=29)$, increased blood creatinine $(29)$, pollakiuria (8), proteinuria (6), dysuria (6), increased blood urea (4), nocturia (2), decreased glomerular filtration rate (1), renal impairment (1), renal disorder (1), renal artery stenosis (1), renal pain (1), dialysis (1), azotemia (1), chromaturia (1), hematuria (1), polyuria (1), and decreased urine output (1). The total number of reports for potential aliskiren-related renal dysfunction events was 95 (6.0\% of total reports). Most of the reports were linked to an aliskiren daily dose of $150 \mathrm{mg}$. Three reports of acute renal failure and three for increased blood creatinine were linked to hospitalization, and two reports of dysuria were associated with disability.

\section{Serious adverse drug reaction reports}

Serious adverse drug reactions are events that occur at any dose resulting in death, a life-threatening episode, initial and prolongation of hospitalization, disability, or congenital anomaly. ${ }^{24}$ A total of 130 reports were considered serious, ie, death $(\mathrm{n}=18)$, life-threatening events $(18)$, requiring hospitalizations (92), resulting in disability (2), and one report requiring an intervention. Reports of serious events related to aliskiren with a reporting frequency of at least two reports during the study period are described in Table 3 . About $38 \%$ of deaths were reported for unknown adverse reactions, $23 \%$ of lifethreatening adverse event reports were related to arrhythmia, and $18 \%$ of inpatient hospitalization reports were linked to angioedema.

\section{Other adverse reactions}

Other aliskiren-related adverse events at a frequency of $\geq 15$ reports in the AERS included hypotension, hyperkalemia, hyponatremia, dyspepsia, diarrhea, abdominal pain, nausea, cough, rash, headache, dizziness, fatigue, asthenia, alopecia, arthralgia, and myalgia. The role of aliskiren in all adverse drug reaction reports was $93 \%$ primary, $5 \%$ secondary, and $2 \%$ concomitant with other drugs.
Table 3 Distribution of serious adverse event reports for aliskiren in the US Adverse Event Reporting System for 2007-2008

\begin{tabular}{|c|c|c|}
\hline Severity category & Adverse event MedDRA term & n (\%)* \\
\hline \multirow[t]{6}{*}{ Death } & Unknown event & $6(37.5)$ \\
\hline & Cerebrovascular accident & $2(12.5)$ \\
\hline & Pulmonary edema & $2(12.5)$ \\
\hline & Cyanosis & $2(12.5)$ \\
\hline & Convulsion & $2(12.5)$ \\
\hline & Angioedema & $2(12.5)$ \\
\hline \multirow[t]{6}{*}{ Life-threatening } & Arrhythmia & $3(23.0)$ \\
\hline & Increased alanine aminotransferase & $2(15.4)$ \\
\hline & Loss of consciousness & $2(15.4)$ \\
\hline & Angioedema & $2(15.4)$ \\
\hline & Atrial fibrillation & $2(15.4)$ \\
\hline & Malaise & $2(15.4)$ \\
\hline \multirow[t]{21}{*}{ Hospitalization } & Angioedema & $12(18.0)$ \\
\hline & Arrhythmia & $5(7.5)$ \\
\hline & Asthenia & $4(6.0)$ \\
\hline & Fluctuation in blood pressure & $4(6.0)$ \\
\hline & Edema & $4(6.0)$ \\
\hline & Increased blood creatinine & $3(4.5)$ \\
\hline & Acute renal failure & $3(4.5)$ \\
\hline & Abdominal pain & $3(4.5)$ \\
\hline & Chest pain & $3(4.5)$ \\
\hline & Hypertension & $3(4.5)$ \\
\hline & Abdominal discomfort & $3(4.5)$ \\
\hline & Cardiac failure & $2(3.0)$ \\
\hline & Diarrhea & $2(3.0)$ \\
\hline & Drug ineffective & $2(3.0)$ \\
\hline & Gastrointestinal hemorrhage & $2(3.0)$ \\
\hline & Hypertensive crisis & $2(3.0)$ \\
\hline & Pulmonary hypertension & $2(3.0)$ \\
\hline & Neutropenia & $2(3.0)$ \\
\hline & Stevens-Johnson syndrome & $2(3.0)$ \\
\hline & Increased alanine aminotransferase & $2(3.0)$ \\
\hline & Cerebrovascular accident & $2(3.0)$ \\
\hline Disability & Dysuria & $2(100)$ \\
\hline
\end{tabular}

Note: *Percentage of reports within severity category.

Abbreviation: MedDRA, Medical Dictionary for Regulatory Activities.

\section{Data mining results}

Compared with other renin-angiotensin-aldosterone system modulators, aliskiren was associated with the highest reporting ratio for angioedema (EBGM 3.9, 95\% CI 3.2-4.7), renal dysfunction (EBGM 3.4, 95\% CI 2.6-4.5), diarrhea (EBGM $4.3,95 \%$ CI 4.2-13.0), and dry cough (EBGM 11.0, 95\% CI 7.8-14.2). Among the groups, aliskiren ranked the second after aldosterone antagonists for hyperkalemia reporting rates (EBGM 7.4, 95\% CI 4.2-13.0) Figure 2 presents the reporting ratios of selected adverse events for aliskiren and other renin-angiotensin-aldosterone system modulators. Analyzing the individual MedDRA terms for angioedema yielded essentially similar EBGM values to the combined MedDRA terms for signs and symptoms of angioedema, with no significant effect on study conclusions. 

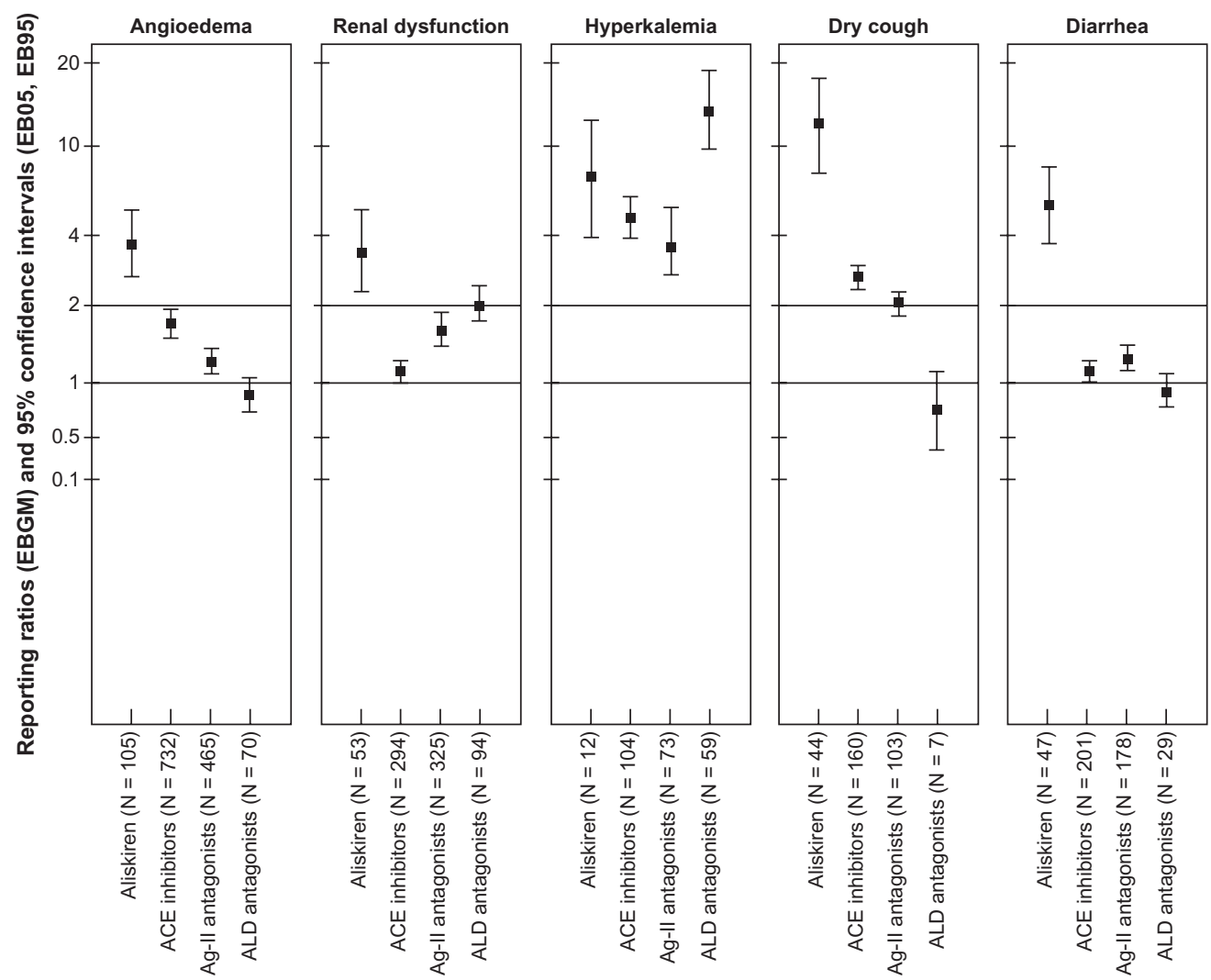

Figure 2 Empiric Bayes geometric mean values and $95 \%$ confidence intervals (EB05, EB95) of selected adverse events for renin-angiotensin-aldosterone system modulators in the US Adverse Event Reporting System for 2007-2008.

\section{Discussion}

The FDA AERS database was utilized to conduct this retrospective pharmacovigilance study for evaluation of the postmarketing safety profile of aliskiren hemifumarate, the first-in-class direct renin inhibitor among the 18 new molecular entities approved by the FDA in $2007 .{ }^{25}$ Reports of adverse reactions to aliskiren (Tekturna, Rasilez) during the period January 2007 through December 2008 were included in the analysis. Aliskiren was associated with a large number of reports of angioedema, renal dysfunction, hyperkalemia, gastrointestinal disorders, and cough. The findings with regard to angioedema and renal dysfunction are consistent with the clinical trials and safety reports received by the European Medicines Agency. ${ }^{13,26-28}$

It is important topoint out that the specificity of adverse events reported in the AERS is not thoroughly established, therefore a causal association between aliskiren, angioedema, and renal impairment cannot be certain. Other coexisting medical conditions and/or comedications could confound the association. Angiotensin-converting enzyme inhibitors have long been in the market and shown to promote angioedema through a surfeit of bradykinin production; similarly, aliskiren does not breakdown bradykinin, which could account for the side effects of dry cough and angioedema. ${ }^{9,29}$ The higher EBGM values for angioedema and renal dysfunction are consistent with clinical studies, and thus are unlikely to be due to detection

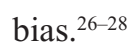

One of the advantages of data mining in the AERS is to provide early indicators of adverse reactions for marketed pharmaceutical products. ${ }^{19,30}$ Premarketing clinical studies usually investigate the drug in specific small samples of patients for short durations. Rare, unlabeled, and serious adverse events may not become evident until the drug enters the market, when a larger number of diverse patients are exposed to the drug in different clinical settings. The capability to estimate EBGM values (reporting ratios) for every drug-event combination in the database is a strength of the data mining approach, which aids in comparing reporting ratios for a specific adverse drug reaction across different drugs. It is important not to interpret such ratios as relative risks or incidence rates. Data mining allows efficient comparisons of drug-event combinations in a large database (clinical trials for such combinations are resource-intensive and timeconsuming). Data mining also enables detection of safety signals for drug-event combinations that might go undetected in a massive database because of the vast number of drugs 
and events involved and the intricacy of the database. It is surprising to find a decline in adverse event reporting for such a novel chemical (Figure 1); this reduction could correspond to a reduction in utilization for multiple reasons, including the novelty of the product, unavailability of updated hypertension treatment guidelines with regard to aliskiren, or the occurrence of side effects. Experiencing adverse reactions discourages prescribers from increasing the dosage, which could partially explain the finding that the majority of reports were associated with aliskiren in daily doses of $150 \mathrm{mg}$.

Furthermore, higher EBGM values reflect a stronger association between the drug and the events. It does not provide evidence of causality between the drug and the event. EBGM points to the relative frequency of angioedema and reports of renal dysfunction for aliskiren, compared with all drugs and adverse event reports in the AERS database during the study period. Likewise, lower EBGM values do not provide evidence of tolerability. Detection bias, reporting bias, and confounding by indication cannot be discounted in AERS analysis. EBGM values can be increased or decreased depending upon the length of time the drug has been on the market and the AERS delay in utilization of MedDRA Preferred Terms codes in the database. ${ }^{19}$ However, the period of analysis for aliskiren reports was brief and the FDA applied a consistent revised version of MedDRA Preferred Terms codes in adverse event documentation during the study period. For a variety of reasons, underreporting of adverse events in the AERS is the major limitation of the database. Therefore, it is likely that the actual number of cases of angioedema and renal failure in the AERS are underestimated. ${ }^{30}$

Development and continuation of postmarketing safety surveillance for new molecular entities is important for establishing the safety and effectiveness of new molecular entities. Three criteria are suggested by the FDA pilot program in order to consider a new molecular entity for postmarketing safety surveillance, ie, the length of time the product has been on the market, the number of adverse event reports in the AERS database, and the clinical indication for which the new molecular entity is prescribed. ${ }^{14}$ In addition to these factors, the inclusion and exclusion criteria for the study sample in premarketing studies for the new molecular entity should be considered as well. For example, the safety of aliskiren with regard to angioedema in African American patients was not studied prior to marketing. ${ }^{26}$

\section{Conclusion}

Treatment with aliskiren hemifumarate (Tekturna, Rasilez) may be associated with angioedema and renal failure. This study shows higher than expected reports of angioedema and renal impairment for aliskiren. Consistent with recommendations from the European Medicines Agency, ${ }^{13}$ the FDA should alert health care professionals about the possibility of encountering angioedema and renal impairment with use of aliskiren. This could be accomplished by a product label change and sending letters to health care professionals warning about cautious administration of aliskiren in patients at risk of acute renal failure, including those with renal artery stenosis or other risks for renal dysfunction, eg, hypovolemia, and cardiac or hepatic disease. Moreover, the precaution section of the product leaflet should clearly state that patients with signs and symptoms of angioedema after using aliskiren should cease aliskiren therapy and seek prompt medical help, and the contraindication section should mention that aliskiren must not be administered to patients who have previously experienced angioedema after using aliskiren. In addition, concomitant use of aliskiren with drugs that worsen renal function and disturb plasma potassium levels should be avoided, in particular, nonsteroidal anti-inflammatory drugs, where both efficacy and renal tolerability of aliskiren are compromised by concomitant administration. ${ }^{13}$ Furthermore, aliskiren-related signs of angioedema, renal failure, and hyperkalemia should be listed on the potential safety signals page of the FDA AERS website, and it is recommended to create a similar listing within the new molecular entity approval history webpage of the FDA. ${ }^{25,31}$

Given the voluntary nature of the AERS, the results of the current hypothesis-screening study should not be causally interpreted as epidemiologic comparison treatment groups. ${ }^{32}$ Robust observational epidemiologic studies, including longitudinal designs, are recommended to establish causality and risk factors for adverse reactions, eg, race. Furthermore, longer durations of postmarketing data are needed to quantify the risks further and examine the safety signals of aliskiren in patients with hypertension.

\section{Acknowledgments}

The author thanks Abraham Hartzema, Department of Pharmaceutical Outcomes and Policy, University of Florida, for his valuable comments and review, and Teba Mohammad, College of Education, University of Florida, for editing the final version of the manuscript.

\section{Disclosure}

The author reports no conflict of interest in this work. Publication of this article was funded in part by the University of Florida Open-Access Publishing Fund (UFOAP). 


\section{References}

1. Food and Drug Administration Center for Drug Evaluation and Research. Manual of policies and procedures: Providing general consumer information on new molecular entities on CDER's website, 2008. Available from: http:/www.fda.gov/downloads/AboutFDA/ReportsManualsForms/ StaffPoliciesandProcedures/ucm078823.pdf. Accessed July 25, 2009.

2. Begaud B. Pharmacovigilance. In: Begaud B. Dictionary of Pharmacoepidemiology. West Sussex, UK: John Wiley and Sons Ltd; 2000.

3. World Health Organization. Pharmacovigilance: Ensuring the Safe Use of Medicines. Geneva, Switzerland: World Health Organization; 2004.

4. Food and Drug Administration Center for Drug Evaluation and Research. Product approval letter, Tekturna HCT. Available from: http://www. accessdata.fda.gov/drugsatfda_docs/appletter/2008/022107s0001tr.pdf. Accessed July 25, 2009.

5. Food and Drug Administration Center for Drug Evaluation and Research. Product approval letter. Available from: http://www. accessdata.fda.gov/drugsatfda_docs/appletter/2007/021985s0001tr.pdf. Accessed July 25, 2009.

6. Novartis Pharmaceuticals Corporation. FDA approves Tekturna HCT as initial treatment in patients unlikely to achieve their blood pressure goal with a single agent. Basel, Switzerland, July 21, 2009. Available from: http://www.novartis.com. Accessed July 25, 2009.

7. Novartis Pharmaceutical Corporation. Novartis receives FDA approval for Valturna, a single-pill combination of valsartan and aliskiren, to treat high blood pressure. Basel, Switzerland, September 17, 2009. Available from: http://www.novartis.com. Accessed September 18, 2009.

8. World Health Organization. Drugs Affecting Renin-Angiotensin-Aldosterone System, Reports of Renal Adverse Events. Geneva, Switzerland: World Health Organization Pharmaceuticals Newsletters 5 and 6; 2008.

9. Sever PS, Gradman AH, Azizi M. Managing cardiovascular and renal risk: The potential of direct renin inhibition. J Renin Angiotensin Aldosterone Syst. 2009;10:65-76.

10. Ibrahim MM. RAS inhibition in hypertension. J Hum Hypertens. 2006;20:101-108.

11. World Health Organization. Aliskiren: Risk of Angioedema and Acute Renal Failure. Geneva, Switzerland: World Health Organization Pharmaceuticals Newsletter 3; 2009.

12. World Health Organization. Aliskiren: New Contraindication and Warning. Geneva, Switzerland: World Health Organization Pharmaceuticals Newsletter 2; 2009.

13. Medicines and Healthcare Products Regulatory Agency. Drug Safety Advice: Aliskiren: Risk of Angioedema and Renal Dysfunction. Drug Safety Update. London, UK: Medicines and Healthcare Products Regulatory Agency; 2009.

14. Food and Drug Administration Center for Drug Evaluation and Research. New molecular entity post-marketing safety evaluation pilot program progress report. Available from: http://www.fda.gov/Drugs/DrugSafety/ PostmarketDrugSafetyInformationforPatientsandProviders/ucm 103470. htm. Accessed July 25, 2009.

15. Rodriguez EM, Staffa JA, Graham DJ. The role of databases in drug postmarketing surveillance. Pharmacoepidemiol Drug Saf. 2001;10:407-410.

16. Food and Drug Administration Center for Drug Evaluation and Research. 2000 Report to the Nation: Improving Public Health Through Human Drugs. Rockville, MD: Food and Drug Administration; 2001.

Therapeutics and Clinical Risk Management

\section{Publish your work in this journal}

Therapeutics and Clinical Risk Management is an international, peerreviewed journal of clinical therapeutics and risk management, focusing on concise rapid reporting of clinical studies in all therapeutic areas, outcomes, safety, and programs for the effective, safe, and sustained use of medicines. This journal is indexed on PubMed Central, CAS,
17. Food and Drug Administration. Quarterly Extract from Adverse Event Reporting System. Springfield, VA: US Department of Commerce, National Technical Information Service; 2001.

18. Food and Drug Administration Adverse Event Reporting System. Latest quarterly data files. Available from: http://www.fda.gov/Drugs/Guidance Compliance-RegulatoryInformation/Surveillance/AdverseDrugEffects/ ucm082193.htm. Accessed June 10, 2009.

19. Szarfman A, Tonning JM, Doraiswamy PM. Pharmacovigilance in the 21st century: New systematic tools for an old problem. Pharmacotherapy. 2004;24:1099-1104.

20. DuMouchel W. Bayesian data mining in large frequency tables, with an application to the FDA spontaneous reporting system (with discussion). Am Stat. 1999;53:177-190.

21. Hartzema AG. Data mining in pharmacovigilance. Presented at: Pharmacoepidemiology and Therapeutic Risk Management Course Lecture. College of Pharmacy, University of Florida, February 6, 2006, Gainesville, FL.

22. Hauben M, Horn S, Reich L. Potential use of data-mining algorithms for the detection of 'surprise' adverse drug reactions. Drug Saf. 2007;30: $143-155$.

23. Lincoln Technologies Inc. WebVDME 5.0 User Guide. March 2005, Wellesley Hill, MA.

24. Food and Drug Administration. Guidance for the industry: Good pharmacovigilance practice and pharmacoepidemiologic assessment. 2005. Available from: http://www.fda.gov/cder/guidance/6359OCC. pdf. Accessed July 25, 2009.

25. Food and Drug Administration. NME drug and new biologic approvals in 2007. Available from: http://www.fda.gov/Drugs/Develop mentApprovalProcess/How-DrugsareDevelopedandApproved/ DrugandBiologicApprovalReports/NMEDrugandNewBiologic Approvals/ucm081690.htm. Accessed June 10, 2009.

26. Product Information. Tekturna (aliskiren hemifumarate). East Hanover, NJ: Novartis Pharmaceuticals Corporation; 2007.

27. Andersen K, Weinberger MH, Egan B, et al. Comparative efficacy and safety of aliskiren, an oral direct renin inhibitor, and ramipril in hypertension: A 6-month, randomized, double-blind trial. J Hypertens. 2008;26:589-599.

28. Oparil S, Yarows SA, Patel S, Fang H, Zhang J, Satlin A. Efficacy and safety of combined use of aliskiren and valsartan in patients with hypertension: A randomized, double-blind trial. Lancet. 2007;370: 221-229.

29. Cromer J, Peker S. Aliskiren (Tekturna), a novel antihypertensive approach to inhibition of the renin-angiotensin-aldosterone system. P T. 2008;33:92-96.

30. Szarfman A, Machado SG, O'Neill RT. Use of screening algorithms and computer systems to efficiently signal higher-than-expected combinations of drugs and events in the US FDA's spontaneous reports database. Drug Saf. 2002;25:381-392.

31. Food and Drug Administration. Potential signals of serious risks/new safety information identified from the adverse event reporting system (AERS). Available from: http://www.fda.gov/Drugs/GuidanceCom plianceRegulatoryInformation/-Surveillance/AdverseDrugEffects/ ucm161063.htm. Accessed July 25, 2009.

32. Rothman KJ, Greenland S, Lash TL. Types of epidemiologic studies. In: Rothman KJ, Greenland S, Lash TL, editors. Modern Epidemiology. 3rd ed. Philadelphia, PA: Lippincott Williams and Wilkins; 2008.

EMBase, Scopus and the Elsevier Bibliographic databases. The manuscript management system is completely online and includes a very quick and fair peer-review system, which is all easy to use. Visit http://www.dovepress.com/testimonials.php to read real quotes from published authors. 